\title{
lodine and doxorubicin, a good combination for mammary cancer treatment: antineoplastic adjuvancy, chemoresistance inhibition, and cardioprotection
}

\author{
Yunuen Alfaro, Guadalupe Delgado, Alfonso Cárabez, Brenda Anguiano and Carmen Aceves
}

\begin{abstract}
Background: Although mammary cancer (MC) is the most common malignant neoplasia in women, the mortality for this cancer has decreased principally because of early detection and the use of neoadjuvant chemotherapy. Of several preparations that cause $M C$ regression, doxorubicin (DOX) is the most active, first-line monotherapeutic. Nevertheless, its use is limited due to the rapid development of chemoresistance and to the cardiotoxicity caused by free radicals. In previous studies we have shown that supplementation with molecular iodine $\left(I_{2}\right)$ has a powerful antineoplastic effect in methylnitrosourea (MNU)-induced experimental models of MC. These studies also showed a consistent antioxidant effect of $\mathrm{I}_{2}$ in normal and tumoral tissues.
\end{abstract}

Methods: Here, we analyzed the effect of $I_{2}$ in combination with DOX treatment in female Sprague Dawley rats with MNU-induced MC. In the first experiment (short) animals were treated with the therapeutic DOX dose (16 $\mathrm{mg} / \mathrm{kg}$ ) or with lower doses (8 and $4 \mathrm{mg} / \mathrm{Kg}$ ), in each case with and without $0.05 \% \mathrm{I}_{2}$ in drinking water. lodine treatment began on day 0 , a single dose of DOX was injected (ip) on day 2, and the analysis was carried out on day 7. In the second experiment (long) animals with and without iodine supplement were treated with one or two injections of $4 \mathrm{mg} / \mathrm{kg}$ DOX (on days 0 and 14) and were analyzed on day 56.

Results: At all DOX doses, the short $\mathrm{I}_{2}$ treatment induced adjuvant antineoplastic effects (decreased tumor size and proliferating cell nuclear antigen level) with significant protection against body weight loss and cardiotoxicity (creatine kinase MB, cardiac lipoperoxidation, and heart damage). With long-term $\mathrm{I}_{2}$, mammary tumor tissue became more sensitive to DOX, since a single injection of the lowest dose of DOX (4 mg/Kg) was enough to stop tumor progression and a second DOX4 injection on day 14 caused a significant and rapid decrease in tumor size, decreased the expression of chemoresistance markers (Bcl2 and survivin), and increased the expression of the apoptotic protein Bax and peroxisome proliferator-activated receptor type gamma.

Conclusions: The DOX-I ${ }_{2}$ combination exerts antineoplastic, chemosensitivity, and cardioprotective effects and could be a promising strategy against breast cancer progression.

Keywords: Mammary cancer, MNU, lodine, Doxorubicin, Chemoresistance, PPARY, Cardioprotection

\footnotetext{
* Correspondence: caracev@unam.mx

Instituto de Neurobiología, Universidad Nacional Autónoma de México,

Campus-Juriquilla, Querétaro 76230, México
} 


\section{Background}

The two factors responsible for most breast cancerrelated deaths are the ability of cancer cells to metastasize and to develop resistance to anti-cancer therapies. Indeed, resistance to chemotherapy is a major obstacle to successful treatment of breast cancer $[1,2]$. Anthracycline antibiotics are among the most effective and commonly used anticancer drugs, and doxorubicin (DOX) in particular is often the first choice to treat mammary cancer. Nevertheless, its use has been limited due to the rapid development of chemoresistance and cardiomyopathic side effects $[1,3]$. The therapeutic activity of DOX results from its intercalating into DNA, thereby inhibiting topoisomerase II and preventing DNA and RNA synthesis [4,5]. With respect to chemoresistance, it is known that DOX-resistant cells exhibit: 1) diminished Topoisomerase II expression, 2) increased production of calcium-dependent protein transglutaminases and of integrins involved in membrane stabilization, and 3) increased expression of anti-apoptotic messengers like $\mathrm{Bcl} 2, \mathrm{Bxl}$, or survivin $[2,6,7]$. The protein survivin (Surv), the smallest member of the inhibitor of apoptosis protein (IAP) family, is expressed and required for normal fetal development but is generally absent in adult tissues. However, re-expression of Surv is observed in numerous human cancers where its presence is associated with enhanced proliferation, metastasis, and a poor prognosis [8].

Short-term adverse effects of DOX occurring within 2-3 days of administration include nausea, vomiting, neutropenia, alopecia, and arrhythmias [9]. A long-term side effect is the cardiomyophathy associated with congestive heart failure $[10,11]$. This chronic cardiotoxicity is likely related to iron oxidation and oxygen free radical formation rather than to antineoplastic mechanisms of the drug, since cardiomyocytes are minimally replicating cells [10]. DOX typically induces dilated cardiomyophathy with microscopic features including myofibrillar loss, mitochondrial and interstitial edema, fibroplasias, etc. Clinical serum biomarkers such as creatine kinase MB (CK-MB) or troponins may increase and serve as important, early predictors of cardiotoxicity $[12,13]$.

Low incidences of mammary cancer and cardiovascular disease have been associated with the high iodine intake in Asian, as compared to Western populations (5280 vs $209 \mu \mathrm{g} /$ day). Seaweeds, such as wakame, nori, or mekabu, are widely consumed in Asian countries and contain high quantities of iodine in several chemical forms $[14,15]$. In recent years several research groups including ours have demonstrated that iodine per se acts as an antioxidant in the whole organism and participates in the physiology and/or pathology of organs that capture iodine, such as thyroid, mammary gland, prostate, and stomach [16-19]. In mammary gland, supplementation with molecular iodine $\left(\mathrm{I}_{2}\right)$, but not iodide $\left(\mathrm{I}^{-}\right)$, alleviates human mastalgia and exerts potent antineoplastic and apoptotic effects on animal and human cancer. When administered over periods of weeks up to years, moderately high concentrations of $\mathrm{I}_{2}$ supplements (3-6 $\mathrm{mg}$ /day) have no deleterious effects on thyroid or general health [20-22]. Although the cellular mechanisms through which iodine exerts these effects have not been elucidated in depth, two hypotheses have been proposed: a direct action involving the antioxidant/oxidant properties of iodine, and an indirect effect through iodolipid formation. In the case of antioxidant/oxidant effects, two sets of data have been obtained showing that: a) at low or moderate concentrations, $\mathrm{I}_{2}$ significantly reduces lipid oxidation either by competing with reactive oxygen species (ROS) for various cellular components, or by neutralizing $\mathrm{HO}$ radicals, and b) at high concentrations, iodine acts as a direct oxidant, dissipating the mitochondrial membrane potential, thereby triggering mitochondrionmediated apoptosis [18,23-25]. The indirect effect was originally postulated for thyroid tissue and involves the formation of iodolipids such as 6-iodo-5-hydroxy8,11,14-eicosatrienoic acid (also called 6-iodolactone; 6-IL) or alpha-iodohexadecanal derived from arachidonic acid (AA) or eicosapentaenoic acid, respectively [26]. Both iodolipids exert apoptotic effects [27], and our group has demonstrated that 6 -IL is present in mammary cancer cells after $I_{2}$ supplement and is a functional ligand of peroxisome proliferator-activated receptor (PPAR) type gamma (PPARy) [28-30]. PPARs are ligand-activated transcription factors, and three subtypes -- PPAR alpha, PPAR beta, and PPAR gamma -have been identified [31]. Although originally described as molecular regulators of lipid metabolism, PPAR $\gamma$ were recently shown to play an important role in cell proliferation, differentiation, and apoptosis in many cancer cell lines including breast, prostate, and non-small-cell lung cancer [32]. Moreover, PPAR $\gamma$ activation potentiates the cytotoxic effect of chemotherapeutic agents such as DOX by inhibiting the expression of anti-apoptotic proteins like Bcl2 and Surv [7] or by delaying the epithelial-mesenchymal transition [33].

In the present work we evaluated the effect of $\mathrm{I}_{2}$ supplement in combination with DOX on the methylnitrosourea (MNU)-induced mammary cancer model. Our results show that a 7 -day $\mathrm{I}_{2}$ supplement exerts a significant antineoplastic adjuvant effect with DOX as well as significant cardioprotection, whereas a 56-day iodine treatment is associated with enhanced DOX sensitivity, increased Bax and PPAR $\gamma$, and decreased $\mathrm{Bcl} 2$ and Surv expression suggesting that iodine, through PPARY expression/activation, induces 
differentiation and impairs the development of chemoresistance.

\section{Results}

\section{Short-term DOX-I $\mathrm{I}_{2}$ combination}

Figure 1 summarizes body weight and tumor growth for animals given the three doses of DOX with and without $\mathrm{I}_{2}$ supplement. The data show that high concentrations of DOX (16 and $8 \mathrm{mg}$ ) were associated with dosedependent weight loss and decreased tumor growth, but the DOX4 and $\mathrm{I}_{2}$ groups showed no changes in body weight gain. DOX4 alone did not decrease tumor growth, whereas the $\mathrm{I}_{2}$ group exhibited a $30 \%$ reduction of tumor size. When DOX and $\mathrm{I}_{2}$ were administered together, a significant and consistent protection against body weight loss was observed in groups treated with high doses of DOX (16 and $8 \mathrm{mg} / \mathrm{Kg}$ ), and tumor size reduction was significantly greater with $\mathrm{I}_{2}$ than without $\mathrm{I}_{2}$ in the DOX16 and DOX4 groups.
Mechanisms involved in the antineoplastic effect of DOX and iodine were analyzed in animals treated with the therapeutic dose of DOX (DOX16 groups). The results showed that either DOX16 or $\mathrm{I}_{2}$ treatments significantly decreased the proliferation rate (measured by PCNA), its combination achieves a higher response than separately (Figure 2 ). Only $I_{2}$ groups $\left(I_{2}\right.$ and DOX16- $\mathrm{I}_{2}$ ) exhibited significant increases in the apoptotic index (measured by Bax/Bcl2, Figure 3). No changes in Surv expression were observed at any dose, and only the group treated with both components (DOX16- $\mathrm{I}_{2}$ ) showed significant increases in PPAR $\gamma$ expression.

\section{Cardioprotective effect}

DOX16 and DOX8 treatments resulted in significant, dose-dependent increases in serum CK-MB activity, whereas DOX4 or $\mathrm{I}_{2}$ groups did not show any changes (Figure 4A). The co-administration of DOX and $\mathrm{I}_{2}$ was accompanied by a significant attenuation of the CK-MB increases generated by the high doses of DOX (DOX-16-

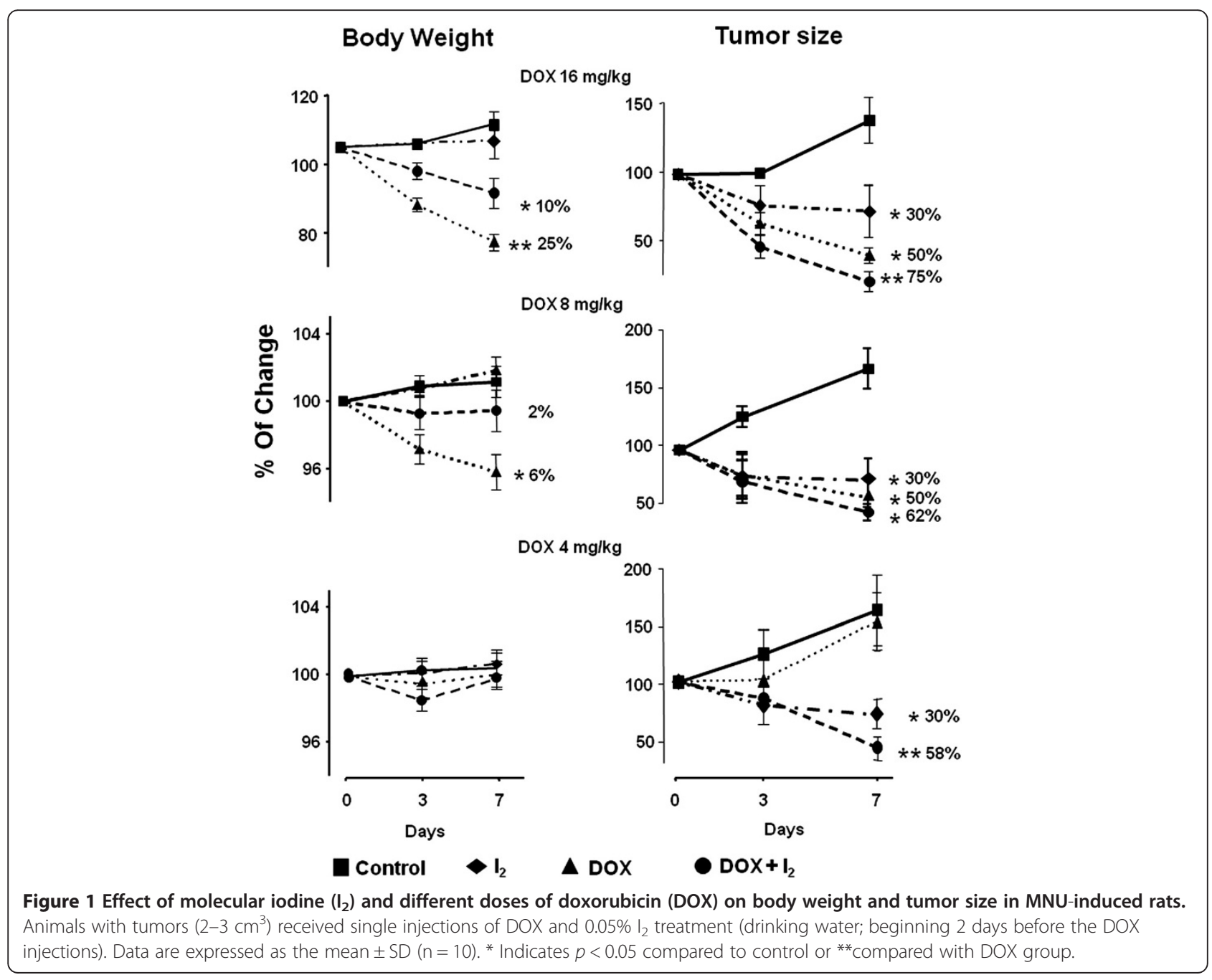



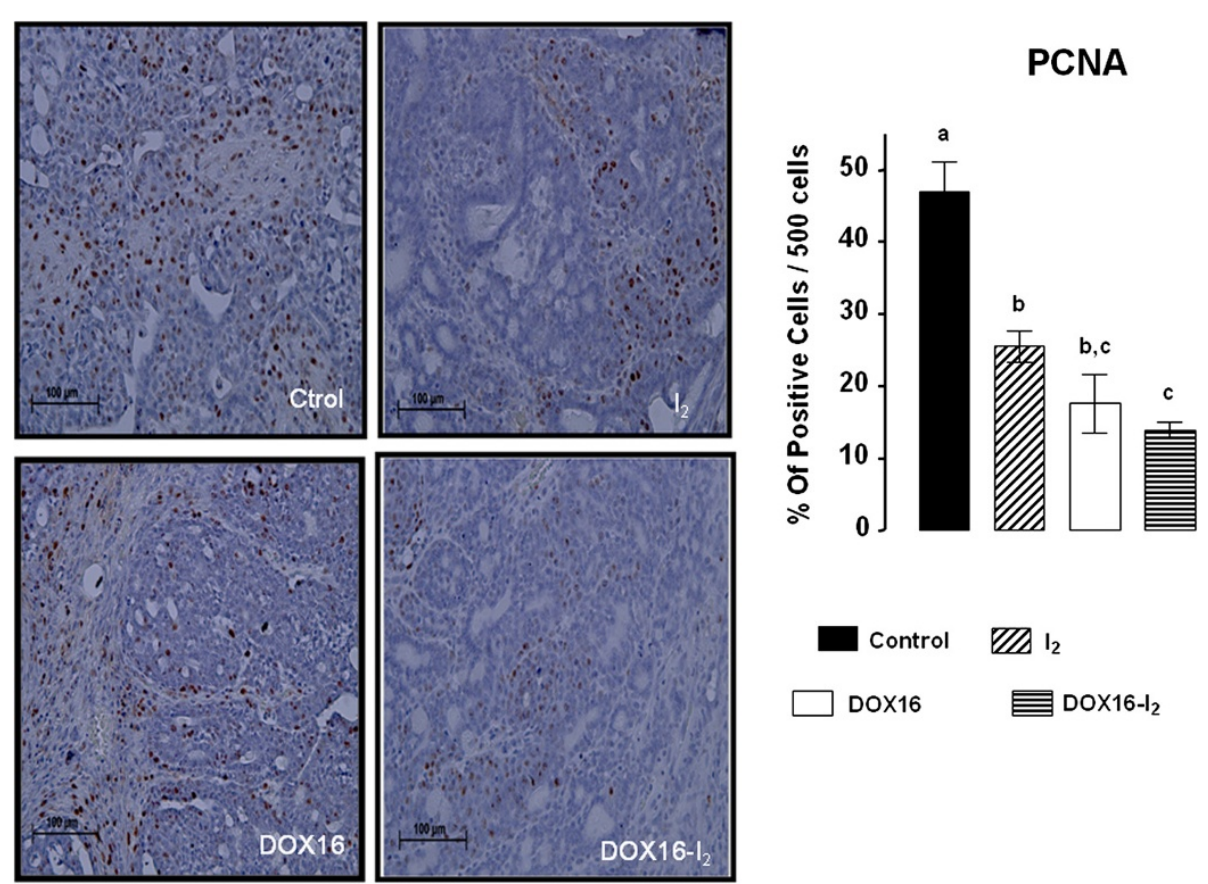

Control שIA $\mathrm{I}_{2}$

DOX16

Figure 2 Proliferation rate. Immunohistochemical presence of PCNA-positive cells in tumors from control and DOX16-treated animals with and without iodine supplement for one week. PCNA-positive cells were revealed with diaminobenzidine (brown stain) and counterstained with hematoxylin (purple stain). Data are expressed as the mean $\pm S D(n=6)$. Means with different letters indicate statistically significant differences $(p<0.05)$.
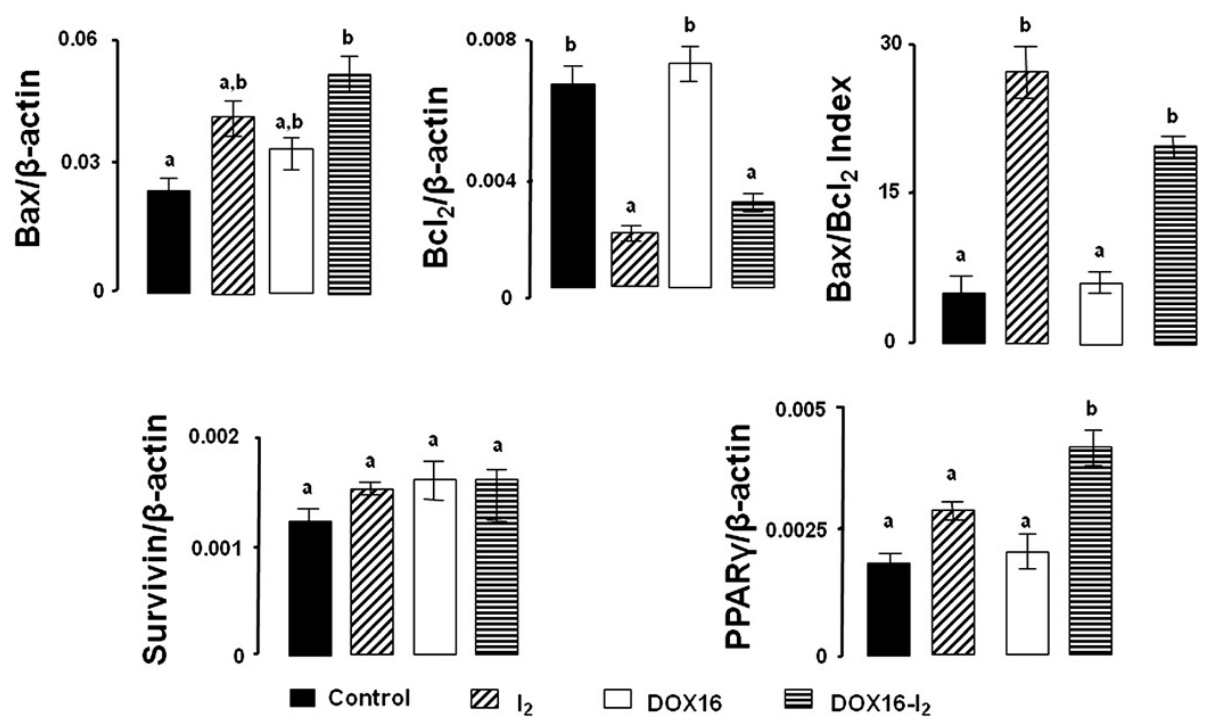

Figure 3 Short-term effect on gene expression. Animals with tumors $\left(2-3 \mathrm{~cm}^{3}\right)$ received a single injection of DOX 16 and were treated with $0.05 \% \mathrm{I}_{2}$ for one week. mRNA expression was measured by qPCR. $\beta$-actin mRNA was amplified to check for RNA quantity and integrity. The experiments were repeated three times with independent RNA samples. Values are expressed as mean \pm SD. Means with different letters indicate statistically significant differences $(p<0.05)$. 


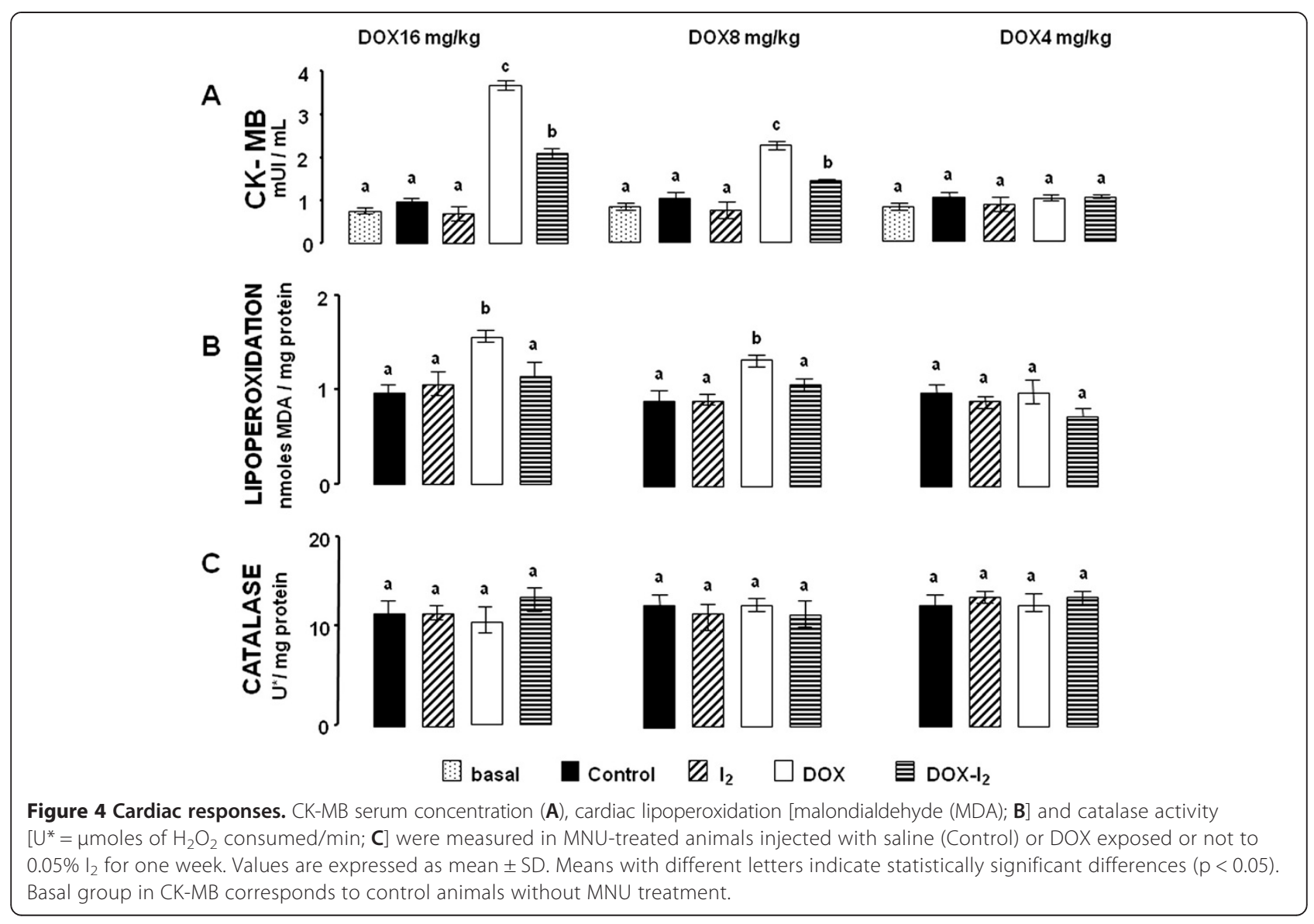

$I_{2}$ and DOX8- $I_{2}$ ). In order to determine if $I_{2}$ cardiac protection was related to its antioxidant effects, lipoperoxidation and catalase enzyme expression were analyzed in heart tissue. Figure $4 \mathrm{~B}$ shows that the high levels of cardiac lipoperoxidation observed in DOX16and DOX8-treated animals were prevented when the animals were supplemented with iodine. In contrast, catalase expression did not change, indicating no participation of this enzyme (Figure 4C). These findings agree with microscopic analysis showing significantly less heart injury in DOX16- $\mathrm{I}_{2}$ than in DOX16 animals, where the principal damage observed was in mitochondria, sarcomeres, and fibers (Additional file 1). Based on the in vitro FRAP assay, the reductive capacity of molecular iodine is 10 times higher than that of ascorbic acid, and 30 to 60 times that of other chemical forms of iodine (Figure 5).

\section{Long-term DOX $4 / \mathrm{I}_{2}$ combination}

In order to analyze the efficacy of long-term $\mathrm{I}_{2}$ supplement (56 days) as a means of preventing the chemoresistance to DOX, we designed a second series of experiments using one or two injections of the lower dose of DOX (DOX4). Figure 6 shows that DOX4 alone exerts a modest and transitory antineoplastic effect after both the first and the second injections, with tumor growth resuming a few days later. In the case of $I_{2}$ supplement, alone or with one initial DOX4 injection $\left(\mathrm{I}_{2}\right.$ or DOX4/ $\left.\mathrm{I}_{2}\right)$, a significant and rapid decrease is observed in the tumor growth (first 7 days), but tumor size remains constant after 14 days. In contrast, the injection of one DOX4 dose after 14 days of $\mathrm{I}_{2}$ supplement $\left(\mathrm{I}_{2}+\right.$ DOX4) or a second injection of DOX4 in the DOX4/ $\mathrm{I}_{2}$ group exerts a significant adjuvant antineoplastic effect that almost eliminates the tumor mass after 42 days in both groups (Figure 6). Comparison of the groups DOX $4+$ DOX4 vs. DOX $4 / \mathrm{I}_{2}+\mathrm{DOX} 4$ shows that repeated, low concentrations of DOX induce increases in the expression of both apoptotic (Bax) and anti-apoptotic messengers ( $\mathrm{Bcl}_{2}$ and survivin), suggesting the development of chemoresistance (Figure 7). In contrast, iodine supplement blocks the induction of antiapoptotic messengers and favors the induction of positive apoptotic signals (Bax and PPAR $\gamma$ expression). The significant increase in the $\mathrm{Bax} / \mathrm{Bcl} 2$ index in 


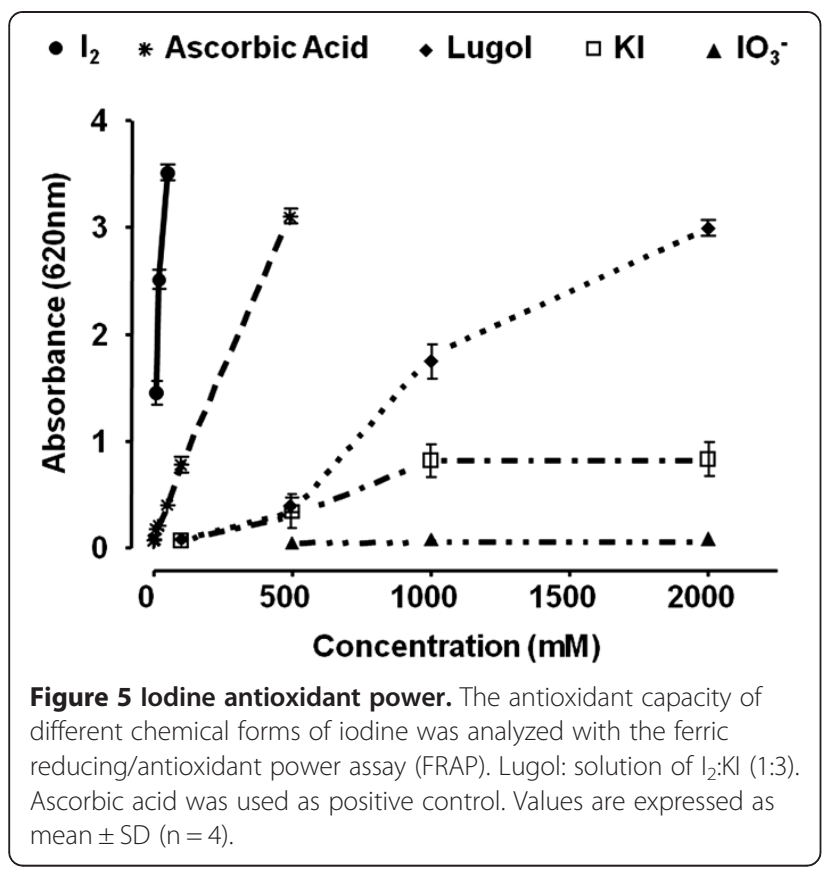

DOX4/ $\mathrm{I}_{2}+\mathrm{DOX} 4$ suggests an enhanced DOX sensitivity that correlates with the marked reduction of tumor mass observed in this group.

\section{Discussion}

Mammary cancer is the most common malignant neoplasia in women worldwide and although many different types of cytotoxic drugs have been developed for its treatment, all are accompanied by adverse effects and in many cases by the development of drug resistance [1]. Thus, there is increasing interest in natural products that can complement conventional medicine. The present study was designed to evaluate the antineoplastic and cardioprotective effects of iodine in conjunction with DOX, the most effective and commonly used chemotherapeutic drug to treat mammary cancer [34]. Our data corroborated previously reported antineoplastic and cardiotoxic effects of DOX [13] and showed that iodine per se exhibited a significant antineoplastic effect in MNU-induced mammary cancer [22,29]. We also found that $\mathrm{I}_{2}$ potentiated the cytotoxic effect of DOX, inhibited the development of chemoresistance to it, and provided significant cardioprotection.

To understand the mechanisms involved in DOX- $\mathrm{I}_{2}$ action, we utilized a variety of molecular techniques to label and measure selected markers. In the present study, we demonstrate that either DOX or $\mathrm{I}_{2}$ alone was able to reduce proliferation by about $50 \%$, but there was no potentiation when the two treatments were administered together. This finding suggests that cellular arrest could not be the prime mechanism involved in the adjuvant effect of $\mathrm{I}_{2}$. In contrast, when the apoptotic index $\left(\mathrm{Bax} / \mathrm{Bcl}_{2}\right)$ was analyzed, iodine had a significant adjuvant effect at both high and low DOX doses. Moreover, the finding that PPAR $\gamma$ expression increased only in $\mathrm{I}_{2}$-supplemented animals suggests that DOX potentiates the PPAR $\gamma$ overpexpression mediated by $\mathrm{I}_{2}$. It is well documented that DOX impairs the synthesis or replication of DNA, resulting in the apoptotic activation of the Bax-caspase pathway [12] and increased expression of anti-apoptotic messengers like $\mathrm{Bcl}_{2}$ and Surv [8], suggesting a complex interaction between apoptotic and anti-apoptotic signaling. Indeed, some authors have proposed that the long-term imbalance in this interaction

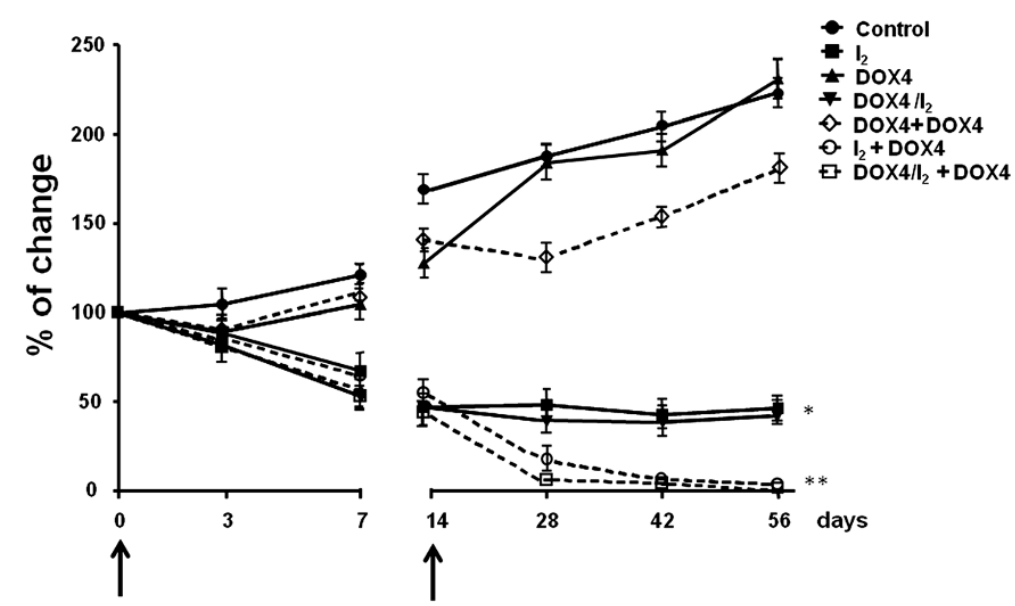

Figure 6 Long-term effect on tumor size (\% change). Animals with tumors $\left(2-3 \mathrm{~cm}^{3}\right)$ received one (day 0 ) and/or two (days 0 and 14) injections of saline (Control) or DOX4 with and without $\mathrm{I}_{2}$ supplement, and tumor size was measured at 56 days. Single injection on day 0 of DOX4 (DOX4); $I_{2}$ alone $\left(I_{2}\right) ; D O X 4+I_{2}\left(D O X 4 / I_{2}\right) ; D O X 4+$ second injection (day 14) of DOX4 (DOX4 + DOX4); $I_{2}$ with only the day 14 injection of DOX4 $\left(I_{2}+\right.$ DOX4), and DOX/I 2 with the second injection of DOX4 on day $14\left(\mathrm{DOX} 4 / \mathrm{I}_{2}+\mathrm{DOX} 4\right)$. Vertical arrows indicated DOX4 injections days. * Indicates $p<0.05$ compared to control, ${ }^{* *}$ compared with $\mathrm{I}_{2}$ and DOX $4 / \mathrm{I}_{2}$ groups. 

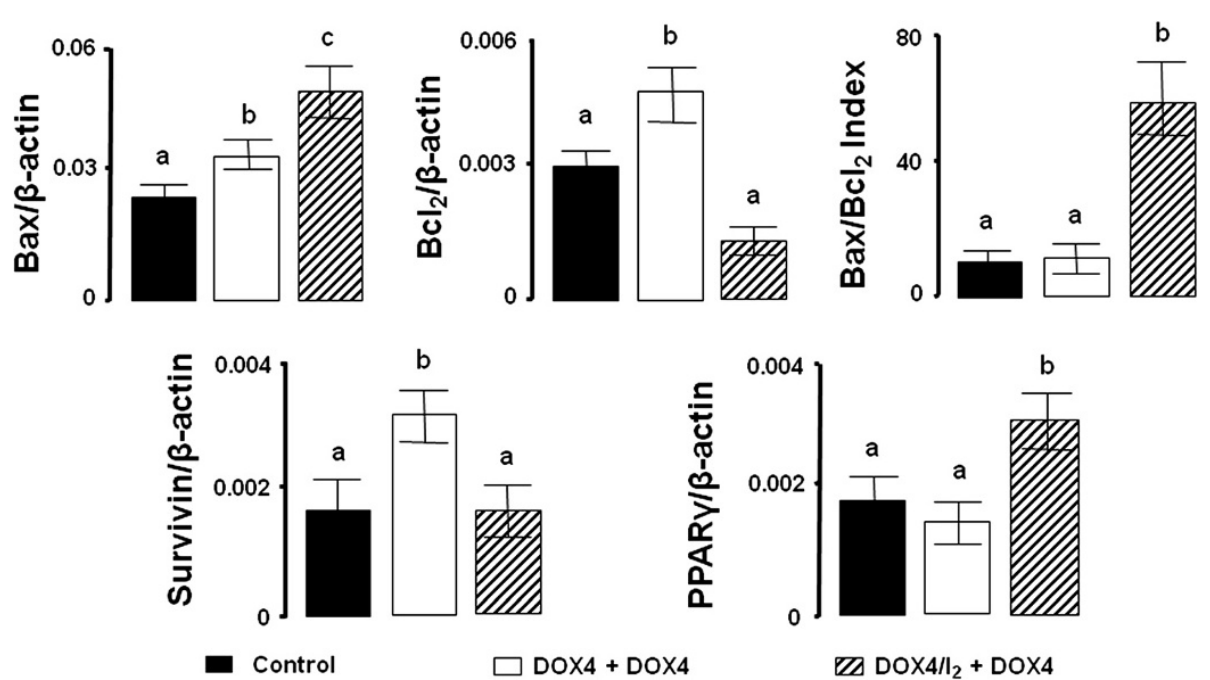

Figure 7 Long-term $\mathrm{I}_{2}$ effect on gene expression. Animals with tumors $\left(2-3 \mathrm{~cm}^{3}\right)$ received two injections of saline (Control) or DOX4 without (DOX4 + DOX4) or with continuous $\mathrm{I}_{2}$ supplement $\left(\mathrm{DOX} 4 / \mathrm{I}_{2}+\mathrm{DOX} 4\right)$ for 56 days. mRNA expression was measured by qPCR. $\beta$-actin mRNA was amplified to check for RNA quantity and integrity. The experiments were repeated three times with independent RNA samples. Values are expressed as mean \pm SD. Means with different letters are statistically significantly $(p<0.05)$.

could explain the development of DOX resistance that occurs when the anti-apoptosis signaling prevails [7]. Molecular iodine administration is accompanied by specific increases in PPARY and Bax, as well as significant decreases or no changes in $\mathrm{Bcl}_{2}$ and Surv expression. These pro-apoptotic patterns of iodine action have been described previously in both in vitro and in vivo models and agree with the well-documented regulation of the Bax/Bcl2-caspase family by PPAR $\gamma[19,32]$. Although a specific PPAR response element has not been identified for these genes, activation of PPAR $\gamma$ provokes a significant decrease in the expression of Blc2 and Surv in mammary tumor cell lines MCF-7 and MDA-MB231 [7]. The direct participation of PPAR $\gamma$ was confirmed using the specific antagonist GW9662 and by the lack of inhibition observed in cells transfected with a PPAR $\gamma$ dominant negative plasmid. The wide spectrum of effects exerted by PPAR $\gamma$ has been explained by its multiple activation pathways and transcriptional regulation of target genes: 1) classical activation to form a heterodimer with the retinoid X receptor (RXR) that binds to specific recognition sites, named the peroxisome proliferator response elements (PPRE), located within the promoter regions of PPAR-responsive genes (ligand-dependent transactivation); 2) in the absence of ligand, PPAR $\gamma$ and RXR could also be associated with transcriptional co-repressor complexes such as nuclear receptor co-repressor (N-CoR) or SMRT (silencing mediator of retinoid and thyroid receptors), which have deacetylation activity (HDAC) and mediate transcription repression (ligand-independent repression), or 3) the ligand-PPAR $\gamma$ complex could repress transcription by inhibiting the activities of other transcription factors, such as members of the NFKB and AP-1 families (ligand-dependent transrepression) [31]. It was proposed that this last repression pathway might down-regulate the expression of Bcl2 and Surv [7].

Several studies suggest that the cardiotoxicity induced by DOX is mediated by reactive oxygen species (ROS) [9]. Two different mechanisms have been identified. The first implicates semiquinone-type free radicals produced in the NADPH-dependent reductase pathway. The second mechanism includes a non-enzymatic reaction of DOX with iron that generates $\mathrm{H}_{2} \mathrm{O}_{2}$; the peroxide, in turn, forms hydroxyl radicals that cause oxidative injury in cellular systems [10]. In one study, the activities of three enzymes capable of detoxifying activated oxygen were determined in both heart and liver; although glutathione peroxidase activity was similar in both tissues, cardiac muscle contained 150 times less catalase and nearly four times less superoxide dismutase than liver. These results showing the low antioxidant resources of the heart, together with its very active metabolism, led the authors to suggest that the heart is particularly vulnerable to damage by free radicals generated in the presence of DOX $[35,36]$. Our present results corroborate the DOX cardiotoxicity: the highest values for CK$\mathrm{MB}$ and LPO activity were in the DOX16 and DOX8 groups. DOX cardiotoxicity was attenuated, however, in the corresponding groups supplemented with $\mathrm{I}_{2}$. The specific mechanism involved in the cardioprotective effect of $\mathrm{I}_{2}$ is not known; indeed, this is the first report that iodine could have this effect. It is well known that other organs besides the thyroid gland are capable of taking up iodine, although heart has not been included in the list [17]. However, in a 
recent article [37] the authors report that myocardiocytes can produce thyroid hormone under ischemia-like conditions. They have shown that thyroglobulin, DUOX1, DUOX2, the sodium-iodide symporter, pendrin, thyroid peroxidase, and the thyroid-stimulating-hormone receptor are transiently up-regulated during this injury, suggesting that this allows cardiomyocytes to initiate cell-protective mechanisms even before local circulation is re-established. Whether a similar mechanism is triggered in these cells during DOX injury has not been explored; however, the high reductive capacity of $\mathrm{I}_{2}$ (FRAP assay) and its preventive effect against heart lipoperoxidation observed in the DOX16- $\mathrm{I}_{2}$ group suggest that iodine might be acting by a direct antioxidant mechanism, neutralizing the free radicals and preventing them from damaging other biomolecules. Indeed, this powerful antioxidant effect has been previously described as a systemic effect on whole organism (17), and is corroborated in the present study by the significant protection against body weight loss observed when animals with high Dox doses (8 and $16 \mathrm{mg}$ ) were treated with $\mathrm{I}_{2}$.

Another main finding of our work was the long-term effect of $\mathrm{I}_{2}$ in animals that received the lowest dose of DOX (DOX4) once or at two different times. We observed that DOX4 alone (one or two injections) could impede tumor growth only in a modest and transitory manner and that the tumoral "escape" was accompanied by increases in anti-apoptotic markers like $\mathrm{Bcl} 2$ and Surv. In contrast, the long-term $\mathrm{I}_{2}$ supplement (at least 14 days) with one or two DOX4 doses significantly enhanced the sensitivity to DOX, decreasing tumor size and blocking the increase of anti-apoptotic markers, suggesting that the pathways to chemoresistance were blocked. Moreover, the significant increases in PPAR $\gamma$ expression in this group, led us to propose that $\mathrm{I}_{2}$ affects the expression and activation of these receptors. The participation of PPAR $\gamma$ in chemoresistance has been extensively documented: PPAR $\gamma$ activation potentiated the cytotoxic effect of chemotherapeutic agents such as DOX by 1) inhibiting the expression of anti-apoptotic proteins like Bcl2 and Surv [7], and 2) inducing differentiation, decreasing cell proliferation, and increasing E-cadherin and beta-catenin expression, indicating the possible interference of PPAR $\gamma$ with processes like the epithelial-mesenchymal transition implicated in acquisition of the invasive phenotype $[33,38,39]$.

\section{Conclusions}

A robust body of evidence supports the notion that moderately high concentrations of molecular iodine exert apoptotic effects in several cancer cells as well as general antioxidant actions in the organism. In the present work we demonstrated that, through activation of PPAR $\gamma$, long-term $I_{2}$ treatment increases the tumor sensitivity to DOX, inhibits chemoresistance, and exerts cardioprotective effects, allowing a four-fold reduction in the therapeutic dose of DOX. These results, together with the adjuvant neoplastic effects of $I_{2}$, lead us to propose Doxorubicin in combination with $\mathrm{I}_{2}$ supplement as a promising strategy against breast cancer progression.

\section{Methods}

\section{Animals}

The studies were performed on virgin female Sprague Dawley $(200 \mathrm{~g})$ rats from the vivarium of the Instituto de Neurobiología, UNAM-Juriquilla. Rats were housed in a temperature-controlled room $\left(21 \pm 1^{\circ} \mathrm{C}\right)$ with a 12-h/12-h light/dark schedule. Food (Purina rat chow; Ralston Purina Co., St. Lous, MO) and water were available ad libitum. All of the procedures followed UNAM and Use Committee Guidelines.

\section{Carcinogen, iodine, and DOX treatments}

At 6 weeks of age, rats were treated to induce mammary tumors with a single ip injection of $50 \mathrm{mg} / \mathrm{kg}$ MNU (Sigma, St. Louis, MO; dissolved in 0.9\% saline, pH 5.0 and activated by heating to $50-60^{\circ} \mathrm{C}$ ) [40]. Rats were weighed and palpated for tumors every week beginning 1 month after MNU exposure. When the tumors grew to $2-3 \mathrm{~cm}^{3}$ (12-16 weeks later), the animals were divided into the following groups: Control, DOX16 (16 $\mathrm{mg} / \mathrm{kg})$, DOX8 (8 $\mathrm{mg} / \mathrm{kg})$, DOX4 (4 mg/kg); DOX16 + $0.05 \% \quad I_{2} \quad\left(\right.$ DOX16- $\left.I_{2}\right), \quad$ DOX $8+0.05 \% \quad I_{2} \quad\left(\right.$ DOX8- $\left.I_{2}\right)$, DOX $4+0.05 \% \mathrm{I}_{2}\left(\mathrm{DOX} 4-\mathrm{I}_{2}\right)$, and $0.05 \% \mathrm{I}_{2}\left(\mathrm{I}_{2}\right)$. Each dose of DOX (Pharmacia \& Upjohn) was administered in a single ip injection. The $\mathrm{I}_{2}$ stock solution is a saturated solution $(1.33 \mathrm{mM})$ of iodine sublimate (J.T. Baker; Edo. de México, Mexico) in distilled water, and the concentration of $0.05 \%$ was confirmed by titration with sodium thiosulfate (40). The drinking water $I_{2}$ solution was delivered in amber bottles that were changed every two days. After correction for sublimation $(<30 \%)$, we estimated that animals consume an intake equivalent to that of Asian populations (5-7 mg/day). The $\mathrm{I}_{2}$ supplement in drinking water began 2 days before DOX and continued for another 5 days until the animals were sacrificed. To determine the long-term effect of DOX4- $\mathrm{I}_{2}$ treatment, a second series of experiments was carried out, with or without $I_{2}$ being supplemented continuously for 56 days, and DOX4 was administered by ip injection on day 0 and/or on day 14. The treatment groups were designed as: single injection day 0 DOX4 (DOX4); $\mathrm{I}_{2}$ alone $\left(\mathrm{I}_{2}\right)$; DOX4 $+\mathrm{I}_{2}\left(\mathrm{DOX} 4 / \mathrm{I}_{2}\right) ; \mathrm{DOX} 4+$ second injection at day 14 of DOX4 (DOX4 + DOX4); $\mathrm{I}_{2}$ with only the day 14 injection of DOX4 $\left(\mathrm{I}_{2}+\mathrm{DOX} 4\right)$, and DOX/I $\mathrm{I}_{2}$ with the second injection of DOX4 on day $14\left(\mathrm{DOX} 4 / \mathrm{I}_{2}+\mathrm{DOX} 4\right)$. A tumor was defined as a discrete palpable mass recorded for least two consecutive weeks. Tumor sizes were measured using 
calipers, and the volumes were calculated by the ellipsoid formula [41].

\section{Immunohistochemistry of proliferating cell nuclear antigen (PCNA)}

Five- $\mu \mathrm{m}$ sections of mammary tumors from rats with or without DOX16 or $\mathrm{I}_{2}$ treatment were deparaffinized, rehydrated, and subjected to antigen retrieval $(10 \mathrm{mM}$ sodium citrate) at $80^{\circ} \mathrm{C}$ for $20 \mathrm{~min}$. After cooling at room temperature, sections were treated with $0.3 \%$ hydrogen peroxide to block endogenous peroxidase activity. Nonspecific binding was blocked with $2 \%$ non-fat dry milk in $20 \%$ fetal bovine serum-PBS solution $\left(1 \mathrm{hr}\right.$ at $\left.37^{\circ} \mathrm{C}\right)$. Sections were incubated at room temperature for $30 \mathrm{~min}$ in a humid chamber with mouse monoclonal anti-rat PCNA, clone PC10 (DakoCytomation, Carpinteria, CA), diluted 1:150). Immune complexes were visualized by goat anti-mouse-immunoglobulin, peroxidase labeled (EnVi$\operatorname{sion}^{\mathrm{Tx}}+$ System, peroxidase, DakoCytomation, Carpinteria, $\mathrm{CA})$. Diaminobenzidine (DAB) was used as the chromogen to generate a brown precipitate after reaction with peroxidase. Sections were counterstained with hematoxylin, rinsed, dehydrated, and mounted with Entellan (Merck, Darmstadt, Germany). Tumor sections were incubated without either the primary or secondary antibody to test for antibody specificity. A brown stain over the nucleus identified PCNA-positive cells. Labeling indices were obtained by counting the number of labeled cells among at least 500 cells per region, and 5 randomly selected regions were analyzed.

\section{Real time PCR}

PPAR $\gamma, B a x, B c l 2$, and Surv expression were analyzed by quantitative real time PCR (qPCR) from tumors after short- (7 day) or long- (56 day) term treatment. Total RNA was obtained using the TRIzol reagent (Life Technologies, Inc., Carlsbad, CA) dissolved in RNAasefree water $(50 \mu \mathrm{L})$, and stored at $-70^{\circ} \mathrm{C}$. The extracted RNA $(2 \mu \mathrm{g})$ was reverse transcribed using oligodeoxythymidine. In order to eliminate genomic DNA contamination, we carried out the RT assay for each individual sample, and as control we used one tube that contained an aliquot from a pool of all samples but no transcriptase enzyme (-RT). We ran a standard PCR for each pair of oligos with two individual samples (random) and the -RT control. The sequence detector system Roto-Gene 3000 (Corbett Research, Mortlake, NSW, Australia) was used to perform qPCR with SYBRgreen as a marker for DNA amplification. The reaction was carried out with $1 \mu \mathrm{L}$ of $\mathrm{cDNA}$ template and the qPCR supermix-UDG kit (Invitrogen), using 40 cycles of threestep amplification $\left(94^{\circ} \mathrm{C}\right.$ for $30 \mathrm{~s}, 55-60^{\circ} \mathrm{C}$ for $30 \mathrm{~s}, 72^{\circ} \mathrm{C}$ for $30 \mathrm{~s}$ ) and the gene-specific primers listed in Table 1. PCR generated only the expected specific amplicon, which was demonstrated in each case by the melting temperature profile (dissociation curve) and by electrophoresis of $5 \mu \mathrm{L}$ of the PCR product through a $2 \%$ agarose gel containing ethidium bromide in TAE buffer. No PCR products were observed in the absence of template. Gene expression was calculated using the D-cycle threshold (Dct) method and normalized to the content of $\beta$-actin, a non-regulated housekeeping gene [42]. The coefficient of variation for this gene was less than $15 \%$ in all RT-PCR assays, indicating that the significant changes observed in the different groups correspond to changes in the experimental genes.

\section{Creatine kinase MB (CK-MB) and catalase activity}

Serum levels of CK-MB were assayed to evaluate cardiac damage, using the commercial kit Humazym M-Test (Human GmbH-65205 Wiesbaden, Germany). Cardiac catalase activity was assayed using the method described by Aebi [43]. Heart tissue was homogenized in assay buffer (50 mM KH $\mathrm{KHO}_{4}, \mathrm{pH}$ 7), and the homogenates were centrifuged at $6000 \times \mathrm{g}$ at $4^{\circ} \mathrm{C}$ for $20 \mathrm{~min}$. The supernatant was diluted with 3 volumes of the assay buffer. Specific activity is expressed as $\mu \mathrm{mol} \mathrm{H}_{2} \mathrm{O}_{2} / \mathrm{min} / \mathrm{mg}$ protein. Protein was determined using the Bradford method (Bio-Rad protein assay; Hercules, CA) with bovine serum albumin (BSA) as standard.

\section{Cardiac lipoperoxidation}

The concentrations of metabolites related to lipoperoxidation were quantified in heart tissue by the thiobarbituric acid reaction and expressed as nanomoles of malondialdehyde (MDA) per mg protein [44]. All manipulations were made rapidly on ice to avoid nonspecific peroxidation. Some modifications to the original method were introduced. To determine basal levels, a sample of homogenate (0.5-1 $\mathrm{mg}$ protein) was incubated for $30 \mathrm{~min}$ at

\section{Table 1 Oligonucleotides}

\begin{tabular}{llll}
\hline Gen & Reference & Sense & Antisense \\
\hline PPAR- $\gamma$ & AF156665 & tcaaacctttaccacggtt & caggctctacttgatcgca \\
B-actin & NM031144 & gtcccagtatgcctctggtcgtac & ccacgctcggtcaggatcttcatg \\
Bax & NM017059 & cagggaggatggctgggaga & ccagacaagcagccgctcacg \\
Bcl-2 & NM016993 & cgaagtgctattggtacctg & tattgtttggggcaggtct \\
Surv & NM022274 & aagccacttgtcccagctt & ctcatccactcccttcctc \\
\hline
\end{tabular}


$37^{\circ} \mathrm{C}$ in a $1-\mathrm{mL}$ volume containing $150 \mathrm{mM}$ Tris buffer, $\mathrm{pH} 7.4$; incubation was stopped by adding $1.5 \mathrm{~mL} 20 \%$ acetic acid (adjusted to $\mathrm{pH} 3.5$ with $\mathrm{KOH}$ ) and $1.5 \mathrm{~mL}$ $0.8 \%$ thiobarbituric acid. Samples were kept for 45 min in a boiling water bath, and $1 \mathrm{~mL} 2 \% \mathrm{KCl}$ was added to each sample at the end of the incubation. The colored complex formed was extracted with butanolpyrimidine $(1: 1, \mathrm{v} / \mathrm{v})$ and detected at $532 \mathrm{~nm}$. Protein was quantified by the Bradford method as above.

\section{lodine antioxidant effect}

Iodine antioxidant power was measured in vitro using the ferric reducing/antioxidant power assay (FRAP) method reported by Benzie and Strain [45] with some modifications. The FRAP reagent was freshly prepared prior to each analysis by combining $300 \mathrm{mM}$ sodium acetate buffer $\mathrm{pH}$ 3.6, $10 \mathrm{mM} \mathrm{2,4,6-tripyridyl-s-triazine} \mathrm{in} 40 \mathrm{mM} \mathrm{HCl}$, and $20 \mathrm{mM}$ ferric chloride in the proportions 10:1:1 (v/v/v). A series of ascorbic acid standards was freshly prepared for each analysis. The FRAP assay was carried out in a microplate (Dynex Technologies, Inc) Individual wells were manually loaded with sodium acetate buffer $(60 \mu \mathrm{L})$ and either ascorbic acid standards or samples $(60 \mu \mathrm{L})$, after which $240 \mu \mathrm{L}$ FRAP reagent was added to each well; absorbance at $620 \mathrm{~nm}$ was determined 4 min later. Different chemical forms of iodine were analyzed and compared to ascorbic acid as standard.

\section{Statistical analysis}

The data are expressed as mean \pm SD. Differences between experimental groups were analyzed using a oneway ANOVA and Tukey's honest significant difference test. Differences with $\mathrm{p}<0.05$ were considered statistically significant.

\section{Histological heart microscopy}

Heart fragments were fixed at $4^{\circ} \mathrm{C}$ by immersion in fixative solution containing 3\% glutaraldehyde either in cacodylate or phosphate buffer at $\mathrm{pH} 7.2$ and processed by routine electron microscopy techniques [46]. Epon 1- $\mu$ m thick sections were obtained with a glass knife and thin sections with a diamond knife either in a Reichert Um03 or RMC ultramicrotome. Thin sections were contrasted with uranyl acetate and lead citrate. One- $\mu \mathrm{m}$ sections were stained with $1 \%$ toluidine blue in $0.1 \mathrm{M}$ sodium borate solution at alkaline $\mathrm{pH}$. Thin sections were observed in a JEOL 1010 electron microscope operated at $80 \mathrm{KV}$.

\section{Additional file}

Additional file 1: Cardiac electron micrography. Animals with tumors $\left(2-3 \mathrm{~cm}^{3}\right)$ received a single injection of DOX16 and/or $0.05 \% \mathrm{I}_{2}$ treatment (drinking water) for 7 days. A, mitochondrion and fiber damage; $B$, laminary rearrangement.

\section{Abbreviations}

MC: Mammary cancer; $\mathrm{I}_{2}$ : Molecular iodine; Dox: Doxorubicin;

MNU: Methylnitrosourea; PPARY: Peroxisome proliferator-activated receptor type gamma; PCNA: Proliferating cell nuclear antigen; 6-IL: 6-iodolactone;

Surv: Survivin; CK-MB: Creatine kinase MB; ROS: Reactive oxygen species; MDA: Malondialdehyde; qPCR: Quantitative real time polymerase chain reaction; FRAP: Ferric reducing/antioxidant power assay;

LPO: Lipoperoxidation.

\section{Competing interests}

The authors declare that they have no competing interests.

\section{Authors' contributions}

YA carried out the tumorogenesis induction and animal experiments and prepared the manuscript. GD performed the real-time polymerase chain reaction analysis. AC performed the microscopic analysis of heart. BA participated in the design of the study and performed the statistical analysis, and CA participated in the study design and coordination. All authors read and approved the final manuscript.

\section{Acknowledgements}

The authors are grateful to Felipe Ortíz, Martin Garcia, Pablo García, Lorena Lopez, and Lourdes Palma for technical assistance, to Francisco Javier Valles and Rafael Silva for bibliographic assistance, to Leonor Casanova and Lourdes Lara for academic support, to Alberto Lara, Omar Gonzalez, Ramon Martinez, and Lorena Ortiz for computer assistance, and to Dr. Dorothy Pless for proofreading. This work was partially supported by grants PAPIIT-UNAM IN201210, IN200813 and CONACYT 174439 and 176911. Yunuen Alfaro was a graduate student of Doctorado en Ciencias Biomédicas, UNAM and received a fellowship from CONACYT 47928

Received: 11 February 2013 Accepted: 10 May 2013

Published: 24 May 2013

\section{References}

1. Goldhirsch A, Wood WC, Senn H-J, Glick GH, Gelbe RD: International consensus panel on the treatment of primary breast cancer. Eur $J$ Cancer 1995, 31:1754-1759.

2. Wang J, Song Y, Xu S, Zhang Q, Li Y, Tang D, Jin S: Down-regulation of ICBP90 contributes to doxorubicin resistance. Eur J Pharma 2011, 656:33-38.

3. Weiss RB: The anthracyclines: will we ever find a better doxorubicin? Semin Oncol 1992, 19:670-686.

4. Gewirtz D: A critical evaluation of the mechanisms of action proposed for the antitumor effects of the anthracycline antibiotics adriamycin and daunorubicin. Biochem Pharmacol 1999, 57:727-741.

5. Deavall DG, Martin EA, Horner JM, Roberts R: Drug-induced oxidative stress and toxicity. J Toxicol 2012, 45:610-618.

6. Herman JF, Mangala LS, Mehta K: Implications of increased tissue transglutaminase (TG2) expression in drug-resistant breast cancer (MCF-7) cells. Oncogene 2006, 25:3049-3058.

7. Woo CC, Loo SY, Gee V, Yap CW, Sethi G, Kumar AP, Tan KHB: Anticancer activity of thymoquinone in breast cancer cells: Possible involvement of PPAR-g pathway. Biochem Pharmacol 2011, 82:464-475.

8. Rios-Petrarca C, Brunetto AT, Duval V, Brondani A, Pereira-Carvalho G, Garicochea B: Survivin as a predictive biomarker of complete pathologic response to neoadjuvant chemotherapy in patients with stage II and stage III breast cancer. Clin Breast Cancer 2011, 11:83-88.

9. Li T, Danelisen I, Singal PK: Early changes in myocardial antioxidant enzymes in rats treated with adriamycin. Moll Cell Biochem 2002, 232:19-26.

10. Lipshultz SE, Colan SD, Gelber RD, Pérez-Atayde AR, Sallan SE, Sander SP Late cardiac effect of doxorubicin therapy for acute lymphoblastic leukemia in chilhood. N Engl J Med 1991, 324:808-815.

11. Swain SM, Whaley FS, Ewer MS: Congestive heart failure in patients treated with doxorubicin. Am Cancer Soc 2003, 97:2869-2879.

12. Stearns V, Singh B, Tsangaris T, Crawford JG, Novielli A, Ellis MJ, Isaacs C, Pennanen M, Tibery C, Farhad A, Slack R, Hayes DF: A prospective randomized pilot study to evaluate predictors of response in serial core biopsies to single agent neoadjuvant doxorubicin or paclitaxel for 
patients with locally advanced breast cancer. Clin Cancer Res 2003, 9:124-133.

13. Takemura G, Fujiwara H: Doxorubicin-induced cardiomyopathy from the cardiotoxic mechanism to management. Prog Cadiovasc Dis 2007, 49:330-352.

14. Teas J, Pino S, Critchley A, Braverman LE: Variability of iodine content in common commercially available edible seaweeds. Thyroid 1983, 14:836-841.

15. Cann SA, Van Netten JP, Van Netten C: Hypothesis: lodine, selenium and the development of breast Cancer. Cancer Causes Control 2000, 11:121-127.

16. Funahashi $\mathrm{H}$, Imai T, Tanaka $Y$, Tsukamara K, Kilumori T: Wakame seaweed suppresses the proliferation of 7, 12-dimethylbenz [a]-anthraceneinduced mammary tumors in rats. Jpn Cancer Res 1999, 90:922-927.

17. Venturi S: Evolutionary significance of iodine. Curr Chem Biol 2011, 5:155-162.

18. Torremante PE, Rosner $\mathrm{H}$ : Antiproliferative effects of molecular iodine in cancers. Curr Chem Biol 2011, 5:168-176.

19. Anguiano $B$, Aceves $C$ : lodine in mammary and prostate pathologies. Curr Chem Biol 2011, 5:177-182.

20. Ghent W, Eskin B, Low D, Hill L: lodine replacement in fibrocystic disease of the breast. Canadian J Surg 1993, 36:453-460.

21. Kessler J: Are there side effects when using supraphysiological levels of iodine in treatment regimens. In Comprehensive Handbook of lodine. Nutritional, endocrine and pathological aspects. Edited by Preedy VR, Burrow GN, Watson RR. San Diego, CA: Academic; 2009:801-810.

22. Garcia-Solis $P$, Alfaro $Y$, Anguiano B, Delgado G, Guzman RC, Nandi S, Diaz-Muñoz M, Vazquez-Martinez O, Aceves C: Inhibition of N-methyl-Nnitrosourea induced mammary carcinogenesis by molecular iodine $\left(\mathrm{l}_{2}\right)$ but not by iodide (KI) treatment Evidence that $\mathrm{I}_{2}$ prevents cancer promotion. Mol Cell Endocrinol 2005, 236:49-57.

23. Arroyo-Helguera O, Delgado G, Anguiano B, Aceves C: Uptake and antiproliferative effect of molecular iodine in the MCF-7 breast cancer cell line. Endocr Related Cancer 2006, 13:1147-1158.

24. Shrivastava A, Tiwari M, Sinha RA, Kumar A, Balapure AK, Bajpai VK, Sharma R, Mitra K, Tandon A, Godbole MM: Molecular iodine induces caspaseindependent apoptosis in human breast carcinoma cells involving mitochondria-mediated pathway. J Biol Chem 2006, 281:19762-19771.

25. Gartner R, Rank P, Ander B: The role of iodine and delta-iodolactone in growth and apoptosis of malignant thyroid epithelial cells and breast cancer cells. Hormones (Athens) 2010, 9:60-66.

26. Dugrillon A, Uedelhoven W, Pisarev M, Bechtner G, Gartner R: Identification of delta-iodolactone in iodide treated human goiter and its inhibitory effect on proliferation of human thyroid follicles. Horm Metabol Res 1994, 26:465-469.

27. Juvenal GJ, Thomasz L, Oglio R, Perona M, Pisarev MA, Rossich L, Salvarredi L: Thyroid: iodine beyond the thyronines. Curr Chem Biol 2011, 5:163-167.

28. Arroyo-Helguera O, Rojas E, Delgado G, Aceves C: Characterization of the cell cycle arrest and signaling pathways involved in the antiproliferative effect of molecular iodine in normal and tumoral breast cells: evidence that 6-iodolactone mediates apoptotic effects. Endocr Related Cancer 2008, 15:1003-1011.

29. Aceves C, García-Solís P, Arroyo-Helguera O, Vega-Riveroll L, Delgado G, Anguiano B: Antineoplastic effect of iodine in mammary cancer. Participation of 6-iodolactone (6-IL) and peroxisome proliferatoractivated receptors (PPAR). Mol Cancer 2009, 8:33-36.

30. Nuñez-Anita RE, Arroyo-Helguera O, Cajero-Juárez M, López-Bojorquez L, Aceves C: A complex between 6-iodolactone and the peroxisome proliferator-activated receptor type gamma may mediate the antineoplastic effect of iodine in mammary cancer. Prostaglands Other Lipid Mediat 2009, 89:34-42.

31. Mansure JJ, Nassim R, Kassouf W: Peroxisome proliferator-activated receptor $\gamma$ in bladder cancer. A promising therapeutic target. Cancer Biol Ther 2009, 8:1-9.

32. Núñez-Anita RE, Cajero-Juárez M, Aceves C: Peroxisome proliferatoractivated receptors. Role of isoform gamma in the antineoplasic effect of iodine in mammary cancer. Curr Cancer Drug Tar 2011, 11:775-786.

33. Aiello A, Pandini G, Frasca F, Conte E, Murabito A, Sacco A, Genua M, Vigneri R, Belfiore A: Peroxisomal proliferator-activated receptor-gamma agonists induce partial reversion of epithelial-mesenchymal transition in anaplastic thyroid cancer cells. Endocrinology 2006, 47:4463-4475.
34. Penault-Llorca F, Cayre A, Bouchet-Mishellany F, Amat S, Feillel V, Le Bouedec G, Ferriere JP, DeLatour M, Chollet P: Induction chemotherapy for breast carcinoma: predictive markers and relation with outcome. Int J Oncol 2003, 22:1319-1325.

35. Doroshow JH, Gershon YL, Myers CE: Enzymatic defenses of the mouse heart against reactive oxygen metabolites. J Clin Invest 1980, 65:128-135.

36. Hossam MA, Abd-Ellah M, Hafez FH: Abatement by naringenin of doxorubicin-induced cardiac toxicity in rats. J Egyptian Nat Cancer 2005, 17:291-300

37. Meischl C, Buermans HP, Hazes T, Zuidwijk MJ, Musters RJ, Boer C, Van Lingen A, Simonides WS, Blankestein MA, Dupuy C, Paulus WJ, Hack CE, Ris-Stalpers C, Roos D, Niessen HW: H9c2 cardiomyoblasts produce thyroid hormone. Am J Physiol Cell Physiol 2008, 294:1227-1233.

38. Bocca C, Bozzo F, Francica S, Colombatto S, Miglietta A: Involvement of PPAR gamma and E-cadherin/beta-catenin pathway in the antiproliferative effect of conjugated linoleic acid in MCF-7 cells. Int J Cancer 2007, 121:248-256.

39. Reka AK, Kurapati H, Narala VR, Bommer G, Chen J, Standiford TJ, Keshamouni VG: Peroxisome proliferator-activated receptor-gamma activation inhibits tumor metastasis by antagonizing Smad3-mediated epithelial-mesenchymal transition. Mol Cancer Ther 2010, 12:3221-3232.

40. Kenkel J: Analytical chemistry for technicians. 2nd edition. Boca Raton, Florida: CRC press LLC; 1994:164-166.

41. Thompson HJ: Methods for the induction of mammary carcinogenesis in the rat using either 7,12-dimethylbenz(a)antracene or 1-methyl-1nitrosourea. In Methods in Mammary Gland Biology and Breast Cancer Research. 8th edition. Edited by Ip M, Asch BB. New York: Kluwer Academic/ Plenum Publisher; 2000:19-29.

42. Fleige $S$, Pfaffl MW: RNA integrity and the effect on realtime qRT-PCR performance. Mol Aspects Med 2006, 27:126-139.

43. Aebi H: Catalase in vitro. Methods Enzymol 1984, 105:121-126.

44. Ottolenghi A: Interaction of ascorbic acid and mitocondrial lipids. Arch Biochem Biophys 1959, 79:355-363.

45. Benzie IF, Strain JJ: The Ferric Reducing Ability of Plasma (FRAP) as a Measure of "Antioxidant Power": The FRAP Assay. Analyt Biochem 1996, 239:70-76.

46. Carabez-T A, Sandoval F, Palma-T L: Ultraestructural changes in tissues produced by inhalation of thinner in rats. Microsc Res Thech 1998, 40:56-62.

\section{doi:10.1186/1476-4598-12-45}

Cite this article as: Alfaro et al: lodine and doxorubicin, a good combination for mammary cancer treatment: antineoplastic adjuvancy, chemoresistance inhibition, and cardioprotection. Molecular Cancer 2013 12:45.

\section{Submit your next manuscript to BioMed Central and take full advantage of:}

- Convenient online submission

- Thorough peer review

- No space constraints or color figure charges

- Immediate publication on acceptance

- Inclusion in PubMed, CAS, Scopus and Google Scholar

- Research which is freely available for redistribution

Submit your manuscript at www.biomedcentral.com/submit
C Biomed Central 